\title{
Razões, benefícios e dificuldades da interação universidade-empresa*
}

Paola Rücker Schaeffer **

Janaina Ruffoni***

Daniel Puffal****

Recebido: 30/09/2013 Versão Revisada (entregue): 10/05/2014 Aprovado: 15/05/2014

\section{RESUMO}

$\mathrm{O}$ artigo analisa razões, benefícios e dificuldades da interação universidade-empresa. Realizouse uma pesquisa survey que investigou interações da área de ciências da computação do Rio Grande do Sul em 2013. Os resultados revelam que as principais razões e benefícios, para as universidades, classificam-se como intelectuais, enquanto para as empresas são as razôes proativas e os benefícios focados em inovação. Em relação às dificuldades, os dois grupos de respondentes destacaram fatores de interesse e institucionais. Para ir além de "pontos de interação", como sugerido pela literatura enquanto uma característica da relação U-E no Brasil, é necessário não apenas expandir quantitativamente o número de interações, mas também ampliar a qualidade dos relacionamentos, remetendo ao entendimento de que essas influenciam diretamente na atividade de geração de conhecimentos e inovações. As questôes apontadas na pesquisa desmistificam a ideia das universidades como "torres de marfim" e das empresas como atores passivos.

* O trabalho apresenta parte dos resultados do projeto de pesquisa Interação Universidade-Empresa no Rio Grande do Sul, financiada pela FAPERGS no Edital 006/2010 sob o registro 10/1554-5.

** Universidade do Vale do Rio dos Sinos (Unisinos). Atualmente mestranda na Universidade Federal do Rio Grande do Sul (UFRGS), Porto Alegre (RS), Brasil. E-mail: paola.rucker@ufrgs.br

*** Universidade do Vale do Rio dos Sinos (Unisinos), São Leopoldo (RS), Brasil. E-mail: janainart@gmail.com

**** Universidade do Vale do Rio dos Sinos (Unisinos), São Leopoldo (RS), Brasil. E-mail: puffal@gmail.com 
PALAVRAS-CHAVE | Interação Universidade-Empresa; Inovação; Ciências da Computação; Rio Grande do Sul

Códigos JEL: O3; O30; O33

\title{
Reasons, benefits and difficulties of the university-industry interaction
}

\begin{abstract}
The article analyzes the reasons, benefits and difficulties of university-industry (U-I) interactions. It was conducted a survey research that investigated interactions of computer science knowledge area of Rio Grande do Sul in 2013. The results show that the main reasons and benefits for universities are classified as intellectuals, whereas for the firms are proactive reasons and innovation benefits. Regarding the difficulties, the two groups of respondents highlighted the interest and institutional factors. To go beyond "points of interaction", as suggested by the literature as a characteristic of the U-I interactions in Brazil, it is necessary not only quantitatively expand the number of interactions, but also increase the quality of relationships, referring to the understanding that these influence directly in the activity of generating knowledge and innovations. The issues raised in the survey demystify the idea of universities as "ivory towers" and firms as passive actors.
\end{abstract}

KEYWORDS | University-Industry Interaction; Innovation; Computer Science; Rio Grande do Sul

JEL-CODES | O3; O30; O33 


\section{Introdução}

A temática desenvolvida neste artigo diz respeito à interação universidade-empresa. Considerando a existência de uma relevância cada vez maior da participação do conhecimento científico na geração de inovações tecnológicas, entende-se que compreender as interações que são estabelecidas para contribuir com o processo de desenvolvimento de inovações, como aquelas que pretendem qualificar recursos humanos, realizar testes de materiais em laboratórios, desenvolver conjuntamente novas ideias, entre outras, é fundamental para que se possa evoluir no entendimento da dinâmica da geração do conhecimento, bem como do papel das universidades neste processo.

A interação entre universidade e empresa, no que tange o propósito de desenvolvimento de conhecimentos, invenções e inovações, passa por uma discussão relativa à dinâmica do Sistema Nacional de Inovação (SNI). Por SNI entende-se um conjunto de instituiçôes privadas e públicas que, por meio de interaçôes, gera e propaga tecnologias no mercado, contribuindo para a riqueza de regióes (FREEMAN, 1987, 1995).

A conexão entre ciência e tecnologia é o aspecto central dos sistemas nacionais de inovação, visto que a ciência é "líder e seguidora" dos avanços tecnológicos (NELSON; ROSENBERG, 1993). Klevorick et al. (1995) apontam a universidade e a ciência como detentoras de oportunidades tecnológicas para a inovação empresarial.

Nos países desenvolvidos, observa-se a presença de um circuito de retroalimentação positiva entre as universidades e as empresas, havendo, assim, um fluxo de informação e de conhecimento que transita nos dois sentidos (COHEN; NELSON; WALSH, 2002). Já no caso da situação brasileira, se averigua uma importante limitação na interação U-E. Há na literatura destaque para o fato de que o SNI brasileiro pode ser considerado completo, mas com pouca dinamicidade e interação entre os atores que o compõem. Logo, o padrão de interação entre universidades e empresas no Brasil restringe-se a "pontos de interação" ou "manchas de interação", nos quais se observam casos de sucesso dispersos e de caráter localizado, com evidentes desigualdades regionais técnico-científicas e de atividades inovativas (ALBUQUERQUE, 2003; RAPINI, 2007; SUZIGAN; ALBUQUERQUE, 2011).

Diante deste contexto, o objetivo do artigo é analisar as principais características, com especial atenção para as razões, os benefícios e as dificuldades, da interação entre universidades e empresas para a geração de inovações tecnológicas. 
Para tanto, utilizou-se uma pesquisa teórico-empírica, empregando o método de survey. A pesquisa de campo foi realizada entre abril e maio de 2013 e investigou grupos de pesquisa e empresas que possuem interação. Optou-se por escolher os grupos de pesquisa da área de conhecimento das ciências da computação do Rio Grande do Sul, pelo fato de esta área apresentar o maior número de grupos com interação nesse Estado, segundo os três últimos censos do Diretório dos Grupos de Pesquisa do CNPq, bem como por ser uma área ainda pouco explorada em estudos a respeito da problemática aqui proposta.

A seção a seguir traz uma revisão da literatura a respeito da interação universidade-empresa (U-E) e suas características relativas a razões, benefícios e dificuldades. Posteriormente apresenta-se a metodologia utilizada e, na sequência, são descritos, analisados e discutidos os resultados. Por fim, são apontadas as considerações finais.

\section{A interação universidade-empresa}

$\mathrm{Na}$ literatura da economia da tecnologia, especialmente nas abordagens sobre SNI, a produção científica e tecnológica é destacada por exercer papel fundamental. O SNI caracteriza-se como uma rede de instituições econômicas, sociais, políticas e organizacionais que intervêm no desenvolvimento, na propagação e na utilização de inovações (EDQUIST, 1997). Assim, um aspecto fundamental desse sistema corresponde às interaçôes estabelecidas entre os atores de maneira a permitir sua atuação de forma coerente (PÓVOA, 2008).

Com o advento da tecnologia moderna, suscitou-se uma complexa relação entre a ciência e a tecnologia, destacando-se, assim, a interação entre a pesquisa acadêmica e a inovação industrial (ROSENBERG; NELSON, 1994; ROSENBERG, 2000). A partir dos estudos realizados por Mowery e Sampat (2005), podem-se apontar os principais resultados da pesquisa acadêmica para a inovação, tais como redes de capacidade científica e tecnológica e protótipos de novos produtos e processos. Essas conclusões remetem ao conceito de universidade empreendedora e conferem a esse ator do SNI um caráter que ultrapassa o papel tradicional atribuído às universidades, compreendido pela oferta de ensino superior e produção de conhecimento (MEYER-KRAHMER; SCHMOCH, 1998; COHEN; NELSON; WALSH, 2002; MOWERY; SAMPAT, 2005; MAZZOLENI; NELSON, 2007).

Já os estudos empreendidos por Klevorick et al. (1995) e Cohen, Nelson e Walsh (2002) buscaram compreender as contribuiçôes da pesquisa acadêmica para a indústria. Concluiu-se que as contribuições ocorrem por meio de diferentes me- 
canismos, variando entre os setores industriais de acordo com a relevância que a ciência possui para cada setor e conforme as capacidades absortivas dos envolvidos (MEYER-KRAHMER; SCHMOCH, 1998). Observou-se, também, que as universidades e os laboratórios de pesquisa exercem uma sutil influência sobre a geração e a conclusão de projetos de pesquisa e desenvolvimento (P\&D) industrial.

\subsection{Razões para a interação}

Arza (2010) classifica as razões para a universidade interagir em intelectuais e econômicas. As primeiras compreendem troca de informaçôes (SEGATTO, 1996; ARZA, 2010), educação (PRAGER; OMENN, 1980; ARZA, 2010), ideias para novas pesquisas (ARZA, 2010; SHIMA; SCATOLIN, 2011), possibilidades novas de publicaçôes com consequente aumento da produtividade acadêmica (ARZA, 2010) e realização da função social da universidade (SEGATTO, 1996). Já as motivações econômicas referem-se à obtenção de fontes de financiamento para a pesquisa (ARZA, 2010; PORTO et al., 2011; SHIMA; SCATOLIN, 2011).

D’Este e Perkmann (2011) classificam as motivações das universidades em quatro categorias: comercialização da tecnologia ou conhecimento; aprendizagem; acesso a financiamentos; e acesso a recursos materiais (PRAGER; OMENN, 1980; SEGATTO, 1996). Outras razões são propostas por Bonaccorsi e Piccaluga (1994) e Porto et al. (2011), os quais concluem que a geração, a transição e a propagação do conhecimento são as principais motivações.

Para as empresas, as quatro razões apontadas são:

- proximidade com cientistas competentes (PRAGER; OMENN, 1980; SEGATTO-MENDES; SBRAGIA, 2002; PORTO et al., 2011; SHIMA; SCATOLIN, 2011);

- vantagens no rateio de custos (PRAGER; OMENN, 1980; PORTO et al., 2011);

- novas tecnologias, conhecimentos e ideias que potencializam a resolução dos problemas que não são solucionados pelo $\mathrm{P} \& \mathrm{D}$ da empresa e a geração de novos produtos e processos (PRAGER; OMENN, 1980; BONACCORSI; PICCALUGA, 1994; SEGATTO-MENDES; SBRAGIA, 2002; PORTO et al., 2011; SHIMA; SCATOLIN, 2011);

- redução da ausência de recursos materiais necessários (BONACCORSI; PICCALUGA, 1994; PORTO et al., 2011; SHIMA; SCATOLIN, 2011). 
Nesse sentido, Arza (2010) divide as razões das empresas em dois tipos: passivas, que utilizam os resultados da interação para a maximização da eficiência operacional; e proativas, que competem à utilização dos recursos da universidade para a geração de atividades inovativas.

\subsection{Benefícios da interação}

Os benefícios para as universidades podem ser seccionados em intelectuais e econômicos, enquanto para as empresas são os de curto prazo, direcionados para a produção, e os de longo prazo, correspondentes aos benefícios da inovação (ARZA, 2010). Meyer-Krahmer e Schmoch (1998) alegam que as principais vantagens da interação, na percepção da universidade, são os fundos de financiamento adicionais, o intercâmbio de conhecimento e as referências para projetos públicos.

No que compete às características dos benefícios da interação U-E nos países emergentes, observam-se diferenças em relação aos países desenvolvidos. De acordo com Dutrénit e Arza (2010), o principal benefício da interação, apontado pelas universidades latino-americanas, corresponde à inspiração para futuras pesquisas científicas. Esse benefício classifica-se como intelectual e é analisado por Bonaccorsi e Piccaluga (1994) também para os países desenvolvidos. No contexto brasileiro, mais especificamente, constata-se que as três principais vantagens listadas pelos grupos de pesquisa das universidades compreendem a formação de recursos humanos e estudantes, a elaboração de teses e dissertações e os novos projetos de pesquisa (RAPINI et al., 2009). Já Fernandes et al. (2010) alegam que as vantagens da interação perpassam, principalmente, os novos projetos de pesquisa, o intercâmbio de conhecimentos e informações e as ideias para novos projetos de cooperação.

Para as empresas, os benefícios centrais são os seguintes: novas ideias, conhecimentos e tecnologias; assistências técnicas; influências sobre a agenda de P\&D; aumento das interaçôes com outras empresas; e informaçôes técnicas para consumidores e fornecedores (FELLER; AILES; ROESSNER, 2002). Restringindo as análises às empresas localizadas em países emergentes, verifica-se que os principais benefícios são aqueles de curto prazo, em detrimento daqueles focados em inovação. Destacam-se, assim, a realização de testes necessários para produtos e processos e a obtenção de conhecimentos tecnológicos para a resolução de problemas de produção (DUTRÉNIT; ARZA, 2010). Corroborando essas observaçōes, Fernandes et al. (2010) afirmam que, no Brasil, a realização de testes é citada como principal 
benefício da interação; contudo, os autores constatam que a segunda vantagem mais referenciada é o uso dos recursos existentes nas universidades, enquanto a transferência de tecnologia para a inovação ocupa a terceira posição.

Por fim, os benefícios apresentam-se como intelectuais ou econômicos, no que compete à percepção das universidades, e em produtivos ou de inovação, conforme as empresas. Não obstante, se averigua, nos estudos que focaram países da América Latina, a predominância dos benefícios intelectuais para as universidades e dos benefícios em produção para as empresas, os quais se encontram relacionados ao curto prazo. Essas características da interação universidade-empresa, nas quais se observam diferenças entre as percepçóes dos envolvidos, revelam e suscitam as dificuldades presentes na interação universidade-empresa, tema abordado na próxima seção.

\subsection{Dificuldades da interação}

$\mathrm{Na}$ concepção das universidades brasileiras, verifica-se que as principais dificuldades da interação referem-se ao alto grau de incerteza dos projetos, à burocracia elevada, ao direito de propriedade de patente e de resultados da pesquisa e às diferenças no nível de conhecimento entre as pessoas da universidade e da empresa envolvidas na cooperação (SEGATTO, 1996; REIS, 1998; FREITAS; MARQUES; SILVA, 2013). Meyer-Krahmer e Schmoch (1998) complementam as análises ao citarem como dificuldades, para as universidades de países desenvolvidos, a orientação das empresas para o curto prazo e as restrições em relação às publicações, dificuldade também suscitada por Tartari e Breschi (2012), que mencionam a perda de liberdade dos pesquisadores no processo de investigação. Arvanitis, Kubli e Woerter (2008) destacam os problemas organizacionais e institucionais, no que tange ao uso dos recursos administrativos, enquanto Shima e Scatolin (2011) expõem a diferença de prioridades e a falta de conhecimento, nas empresas, das atividades realizadas nas universidades.

Para as empresas localizadas no Brasil, as principais barreiras dizem respeito à localização geográfica da universidade, à burocracia universitária, à duração muito longa de projetos e às diferenças no nível de conhecimento entre as pessoas da universidade e da empresa envolvidas na cooperação (SEGATTO, 1996). Feller, Ailes e Roessner (2002) apontam que as dificuldades mais preponderantes no processo de interação resumem-se às diferenças entre as universidades e as empresas, no que se refere a seus valores, missões e prioridades, sendo que a definição dos direitos 
de propriedade intelectual apresentou-se como uma barreira relativamente pouco importante.

Observa-se, dessa forma, um consenso entre a percepção das universidades e das empresas em relação a algumas dificuldades intrínsecas ao processo de interação. Questões como burocracia universitária, duração dos projetos, diferenças de nível de conhecimento, localização geográfica e definição dos direitos de propriedade e de patentes são mencionadas pelos dois envolvidos. No Brasil, as principais dificuldades referem-se à burocracia por parte da universidade e à diferença de prioridades.

Por conseguinte, propôs-se a divisão das variáveis que compõem as razões, os benefícios e as dificuldades em categorias, adaptando-se o modelo sugerido por Arvanitis, Kubli e Woerter (2005, 2008). A síntese apresentada no Quadro 1 fundamentou a construção do instrumento de pesquisa e é retomada na discussão dos resultados.

\section{QUADRO 1}

Síntese da pesquisa

\begin{tabular}{|c|c|c|c|}
\hline Conceitos & Definiçóes & $\begin{array}{l}\text { Categorias de } \\
\text { variáveis (1) }\end{array}$ & Autores \\
\hline \multirow{4}{*}{ Razóes } & \multirow{4}{*}{$\begin{array}{l}\text { Inexistência } \\
\text { de capacidades } \\
\text { internas } \\
\text { suficientes para } \\
\text { a concretização } \\
\text { da estratégia } \\
\text { organizacional } \\
\text { que fundamenta } \\
\text { a busca por fontes } \\
\text { externas }\end{array}$} & $\begin{array}{l}\text { Conhecimento e } \\
\text { tecnologia }\end{array}$ & $\begin{array}{c}\text { Prager e Omenn (1980), } \\
\text { Bonaccorsi e Piccaluga (1994), } \\
\text { Segatto (1996), } \\
\text { Segatto-Mendes e Sbragia (2002), } \\
\text { Arza (2010), D’Este e Perkmann } \\
\text { (2011), } \\
\text { Porto et al. (2011), Shima e } \\
\text { Scatolin (2011) }\end{array}$ \\
\hline & & Acesso a recursos & $\begin{array}{c}\text { Prager e Omenn (1980), } \\
\text { Bonaccorsi e Piccaluga (1994), } \\
\text { Arza (2010), } \\
\text { Porto et al. (2011), Shima e } \\
\text { Scatolin (2011) }\end{array}$ \\
\hline & & Industrial & $\begin{array}{c}\text { Prager e Omenn (1980), } \\
\text { Bonaccorsi e Piccaluga (1994), } \\
\text { Segatto-Mendes e Sbragia (2002), } \\
\text { D'Este e Perkmann (2011), } \\
\text { Porto et al. (2011), Shima e } \\
\text { Scatolin (2011) }\end{array}$ \\
\hline & & Institucional & $\begin{array}{c}\text { Segatto (1996), D’Este e Perkmann } \\
\text { (2011) }\end{array}$ \\
\hline
\end{tabular}

(continua) 
QUADRO 1

Síntese da pesquisa

\begin{tabular}{|c|c|c|c|}
\hline Conceitos & Definiçóes & $\begin{array}{l}\text { Categorias de } \\
\text { variáveis (1) }\end{array}$ & Autores \\
\hline \multirow{4}{*}{ Benefícios } & \multirow{4}{*}{$\begin{array}{l}\text { Para as } \\
\text { universidades, } \\
\text { os benefícios } \\
\text { podem ser de } \\
\text { caráter intelectual } \\
\text { ou econômico, } \\
\text { enquanto para as } \\
\text { empresas podem } \\
\text { ser de produção } \\
\text { ou inovação }\end{array}$} & Institucional & $\begin{array}{l}\text { Feller, Ailes e Roessner (2002), } \\
\text { Rapini et al. (2009), Fernandes et } \\
\text { al. (2010) }\end{array}$ \\
\hline & & Produtos/processos & $\begin{array}{c}\text { Dutrénit e Arza (2010), Fernandes } \\
\text { et al. (2010) }\end{array}$ \\
\hline & & Projetos & $\begin{array}{l}\text { Bonaccorsi e Piccaluga (1994), } \\
\text { Meyer-Krahmer e Schmoch } \\
\text { (1998), Feller, Ailes e Roessner } \\
\text { (2002), Rapini et al. (2009), } \\
\text { Dutrénit e Arza (2010), Fernandes } \\
\text { et al. (2010) }\end{array}$ \\
\hline & & $\begin{array}{l}\text { Recursos } \\
\text { financeiros }\end{array}$ & Meyer-Krahmer e Schmoch (1998) \\
\hline \multirow{5}{*}{ Dificuldades } & \multirow{5}{*}{$\begin{array}{l}\text { Barreiras que } \\
\text { dificultam e } \\
\text { restringem o } \\
\text { processo de } \\
\text { cooperação entre } \\
\text { universidades e } \\
\text { empresas }\end{array}$} & Institucional & $\begin{array}{l}\text { Segatto (1996), Reis (1998), } \\
\text { Meyer-Krahmer e Schmoch } \\
\text { (1998), Feller, Ailes e Roessner } \\
\text { (2002), Arvanitis, Kubli e Woerter } \\
\text { (2008), Shima e Scatolin (2011), } \\
\text { Tartari e Breschi (2012), Freitas, } \\
\text { Marques e Silva (2013) }\end{array}$ \\
\hline & & $\begin{array}{l}\text { Independência } \\
\text { científica }\end{array}$ & Tartari e Breschi (2012) \\
\hline & & Interesses & $\begin{array}{l}\text { Segatto (1996), Reis (1998), } \\
\text { Meyer-Krahmer e Schmoch } \\
\text { (1998), Shima e Scatolin (2011), } \\
\text { Freitas, Marques e Silva (2013) }\end{array}$ \\
\hline & & Recursos humanos & $\begin{array}{l}\text { Segatto (1996), Reis (1998), } \\
\text { Shima e Scatolin (2011) }\end{array}$ \\
\hline & & Geografia & Segatto (1996) \\
\hline
\end{tabular}

(1) As categorias de variáveis foram elaboradas a partir de Arvanitis, Kubli e Woerter (2005, 2008).

Na próxima seção apresenta-se o método de pesquisa organizado em cinco etapas.

\section{Metodologia}

O presente estudo caracteriza-se por ser uma pesquisa teórico-empírica que utilizou o método survey. As atividades realizadas para a execução da pesquisa foram diversas e estão organizadas em cinco etapas consecutivas descritas na Figura 1. 
FIGURA 1

Etapas metodológicas

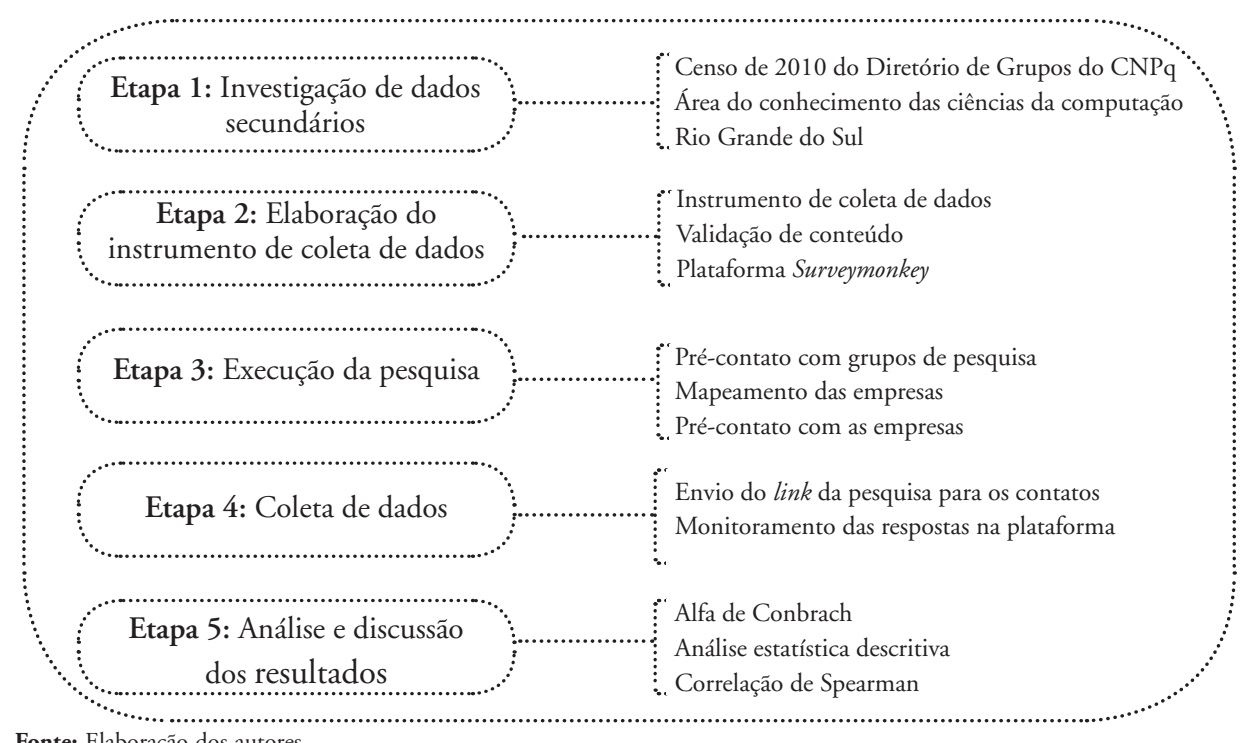

Fonte: Elaboração dos autores.

A seguir estão descritas as atividades realizadas em cada uma das cinco etapas.

Etapa 1: análise dos dados disponíveis no Censo de 2010 do Diretório de Grupos de Pesquisa (DGP) do CNPq para a definição dos grupos e das empresas que seriam investigados. A escolha pelo Estado do Rio Grande do Sul justifica-se por esse deter o segundo maior contingente de grupos de pesquisa do país que declararam ter interação com o setor produtivo (12\%). A partir disso, foi escolhida a área de conhecimento das Ciências da Computação por ter apresentado o maior número absoluto de grupos de pesquisa (30) que declararam ter interação com o setor produtivo nos três últimos censos do DGP/CNPq (2006, 2008 e 2010).

Etapa 2: foram aplicados dois questionários, um aos grupos de pesquisa e outro às empresas, os quais foram elaborados com base no instrumento de pesquisa construído para o projeto "Interações de Universidades e Institutos de Pesquisa com Empresas no Brasil" e levando-se em conta outras variáveis específicas sobre razões, benefícios e dificuldades da interação. A validação dos instrumentos foi feita com pré-testes presenciais e virtuais. A pesquisa foi

1 A pesquisa mencionada foi coordenada pelo Prof. Wilson Suzigan (DPCT/Unicamp) e pelo Prof. Eduardo da Motta e Albuquerque (Cedeplar/UFMG). O projeto obteve recursos da Fapesp (processo 06/58878-8) e do CNPq (processo n. 478994/2006-0). 
realizada com a ferramenta Surveymonkey, que é uma plataforma on-line que auxilia na construção e disponibilização de questionário na Internet.

Etapa 3:² para a execução da investigação, os grupos de pesquisa foram contatados por telefone e foi enviado por e-mail o link do questionário on-line. Com as empresas foi efetuado o mesmo processo, mas o contato foi aquele indicado pelos líderes dos grupos de pesquisa. A amostra foi composta por 32 grupos (aos 30 grupos apresentados na Tabela 1 , adicionaram-se mais dois que foram informados nos contatos telefônicos realizados), dos quais 20 responderam o questionário $(62,5 \%)$. Os grupos de pesquisa respondentes indicaram 34 empresas e nomearam as pessoas responsáveis pela interação para 26 delas, sendo que o total de respostas obtidas foi de 16 (61,5\%).

Etapa 4: para medir as variáveis de cada um dos constructos, foi utilizada uma escala Likert de importância com número par de categorias, acrescentada da opção sem condiçôes de opinar. A escolha por uma escala par justifica-se pelo objetivo de forçar o respondente a se posicionar (HAIR et al., 2005). Obtiveram-se Alfas de Cronbach de 0,782 (grupos de pesquisa) e 0,660 (empresas), para o constructo razôes, 0,895 (grupos de pesquisa) e 0,785 (empresas), para beneficios, e 0,950 (grupos de pesquisa) e 0,895 (empresas), para as dificuldades, resultados que garantem confiabilidade da escala utilizada.

Etapa 5: foi feita uma análise estatística descritiva das respostas e analisadas hipóteses plausíveis que sugerem associações entre as principais razões, benefícios e dificuldades por meio da Correlação de Spearman. ${ }^{3}$

\section{Resultados e análise}

Nesta seção são caracterizados os grupos de pesquisa e as empresas respondentes, bem como apresentada uma análise estatística dos três constructos propostos pelo estudo.

No que compete à caracterização dos grupos de pesquisa, observa-se que dez

2 No que diz respeito à existência de vieses na definição da amostra, deve-se considerar uma possível defasagem na base de dados utilizada, no sentido de que alguns grupos podem ter finalizado as interaçōes que possuíam na época do preenchimento do Censo e outros podem ter iniciado relacionamentos posteriormente, os quais não foram captados na base de dados utilizada. Em relação às empresas, ressalta-se que a amostra foi definida de acordo com as respostas dos grupos de pesquisa a respeito das interaçōes mais importantes. Isso permitiu uma eficiente busca de informaçōes no survey, mas pode ter resultado em um viés referente a uma ênfase maior nas respostas das empresas nos pontos positivos da interação em detrimento de outros.

3 Apesar de a correlação de Spearman tipicamente resultar em um coeficiente mais baixo, se comparada com a correlação de Pearson, ela foi utilizada por se tratar de dados mensurados com escalas ordinais ou nominais, conforme recomenda Hair et al. (2005, p. 317). 
grupos são de instituições públicas e dez de instituições privadas. A UFRGS detém o maior contingente de grupos respondentes (7), seguida da PUC-RS com cinco grupos. As demais universidades - Unisinos, UPF, IFRS, UNISC, UFSM e FURG - completam o grupo de respondentes.

Quando analisado o tempo de existência de cada um dos grupos, verifica-se que eles possuem, em média, 12 anos de formação; contudo, identifica-se uma grande variação nesse dado, pois há grupos com quatro anos de existência e outros com 30 anos.

As interações ocorrem geralmente com firmas localizadas na Região Metropolitana de Porto Alegre (RMPA), as quais representam 44\% do total das empresas indicadas pelos grupos de pesquisa investigados. As demais estão localizadas em outros municípios do Estado (24\% das empresas), em outros Estados da Região Sul (6\%), na Região Sudeste (14\%) ou ainda no exterior, mais especificamente nos Estados Unidos e na França (12\%). Assim, os grupos de pesquisa afirmaram que 68\% das interações que estabelecem são com empresas do Rio Grande do Sul.

É importante destacar aqui que esse resultado encontrado corrobora as observaçôes de Costa, Ruffoni e Puffal (2011). Ao analisarem as informações referentes às empresas que tinham interação com universidades, os autores observaram que a maior parte das empresas investigadas mantinha vínculos apenas com universidades e institutos de pesquisa localizados no próprio Rio Grande do Sul, indicando, de alguma forma, que a proximidade espacial exerce alguma influência na definição dos parceiros, ainda que esse elemento não seja suficiente para explicar a totalidade das relações.

Em relação ao número de empresas com as quais os grupos interagem, as respostas indicam uma média de 2,5 empresas por grupo. Diferem dessa média três grupos de pesquisa, que afirmaram não possuir interação atualmente, e outros quatro grupos, que possuem quatro ou cinco interaçôes com empresas cada um. Vale destacar que a média de 2,5 interações por grupo de pesquisa na área de ciências da computação é superior à média estadual de interações por grupos de pesquisa, conforme o Censo do DGP de 2010, que é de 1,85 empresa.

Já as empresas respondentes caracterizam-se por estarem localizadas, principalmente, na RMPA $(56,2 \%)$, sendo que as demais estão situadas no restante do Estado (37,5\%) ou em Santa Catarina (6,3\%).

De acordo com a classificação de porte de empresa proposta pelo Sebrae, baseada no número de empregados, observa-se que, entre as empresas de serviço, há uma micro, quatro pequenas, uma média e três grandes, enquanto entre as empresas 
industriais, há duas pequenas e cinco médias. Essas empresas possuem, em média, 17 pessoas envolvidas com as atividades de $\mathrm{P} \& \mathrm{D}$, destacando-se cinco empresas que têm 20 pessoas ou mais nessa atividade.

Em relação à atividade econômica das empresas respondentes, 56,2\% foram classificadas como atividades dos serviços de tecnologia da informação. As demais estão distribuídas, principalmente, nas categorias de fabricação de equipamentos de informática $(12,5 \%)$ e de fabricação de produtos químicos (12,5\%).

No que compete à interação com universidades, observou-se que as empresas interagem, em média, com 2,2 instituições, sendo que essas interações iniciaram-se, em média, há 3,6 anos, não existindo na amostra nenhuma empresa que tenha interações há mais de cinco anos. Entre as universidades apontadas como as mais importantes pelas empresas, 45,8\% estão localizadas na RMPA, 41,7\% no restante do Estado do Rio Grande do Sul, 4,2\% no Nordeste e 8,3\% no exterior, mais especificamente no Canadá e na França. ${ }^{4}$ Novamente identifica-se a proximidade geográfica entre os atores como um elemento que caracteriza as interaçôes. O tipo de relacionamento mais presente corresponde aos projetos de $\mathrm{P} \& \mathrm{D}$ em colaboração com a universidade, com resultados de uso imediato, assim como aos projetos de P\&D complementares às atividades de inovação da empresa e aos treinamentos e cursos.

Em relação à iniciativa para o estabelecimento das interações, na percepção dos grupos de pesquisa, o pesquisador (12 respostas) é o responsável pela maior parte das iniciativas, enquanto a empresa ocupa a segunda posição (dez respostas). $\mathrm{Na}$ visão das empresas, porém, quem mais frequentemente tem a iniciativa para a interação é ela mesma (nove respostas). Ressalta-se que essa questão era de múltipla escolha e que resultados semelhantes, nos quais se observa que cada um dos envolvidos aponta a si mesmo como quem teve a iniciativa para o relacionamento, já haviam sido constatados por Shima e Scatolin (2011).

No que diz respeito às razões das interaçôes U-E, constatou-se, conforme a Tabela 1, que os principais motivos para os grupos de pesquisa interagirem com empresas compreendem as ideias para novos projetos de cooperação, os recursos financeiros privados e os novos produtos e artefatos. Os equipamentos e instrumentos de uso compartilhado foram avaliados pelos pesquisadores como as razões menos importantes para o relacionamento.

4 Vale observar que as respostas relatadas são diferentes daquelas coletadas com os líderes dos grupos de pesquisa, pois os respondentes informaram a respeito de interaçôes que estabelecem e não sobre uma interação em específico. Assim, por exemplo, as universidades mais importantes para as empresas não necessariamente serão aquelas dos grupos de pesquisa que as indicaram. 
TABELA 1

Grupos de pesquisa e empresas, segundo razões para a interação universidade-empresa

Estado do Rio Grande do Sul - 2013

\begin{tabular}{|c|c|c|c|c|c|c|}
\hline \multirow[b]{2}{*}{ Razóes para a interação } & \multicolumn{3}{|c|}{ Grupos de pesquisa } & \multicolumn{3}{|c|}{ Empresas } \\
\hline & $\begin{array}{l}\text { Média } \\
(1)\end{array}$ & $\begin{array}{l}\text { Desvio- } \\
\text { padrão } \\
(1)\end{array}$ & $\begin{array}{l}\text { N. de } \\
\text { respon. }\end{array}$ & $\begin{array}{l}\text { Média } \\
(1)\end{array}$ & $\begin{array}{l}\text { Desvio- } \\
\text { padrão } \\
\text { (1) }\end{array}$ & $\begin{array}{l}\text { N. de } \\
\text { respon. }\end{array}$ \\
\hline $\begin{array}{l}\text { R1 - Ideias para novos projetos de } \\
\text { cooperação }\end{array}$ & 3,7 & $\mathbf{0 , 7}$ & 20 & $-(2)$ & $-(2)$ & \\
\hline R2 - Recursos financeiros privados (3) & 3,7 & 0,6 & 20 & & & \\
\hline R3 - Recursos financeiros públicos (3) & 3,4 & 0,7 & 20 & 2,8 & 1,0 & 16 \\
\hline R4 - Novos produtos e artefatos & 3,6 & 0,6 & 20 & 3,1 & 0,7 & 15 \\
\hline $\begin{array}{l}\text { R5 - Intercâmbio de conhecimentos } \\
\text { ou informações }\end{array}$ & 3,5 & 0,5 & 20 & 3,4 & 0,5 & 15 \\
\hline R6 - Formação de RH e estudantes & 3,5 & 0,8 & 20 & 3,7 & 0,4 & 16 \\
\hline R7 - Novas redes de relacionamento & 3,5 & 0,6 & 20 & $-(2)$ & $-(2)$ & \\
\hline R8 - Novos projetos de pesquisa & 3,5 & 0,8 & 20 & $-(2)$ & $-(2)$ & \\
\hline $\begin{array}{l}\text { R9-Recebimento de insumos para a } \\
\text { pesquisa }\end{array}$ & 3,4 & 0,7 & 19 & $-(2)$ & $-(2)$ & \\
\hline R10 - Novos processos industriais & 3,4 & 0,6 & 17 & 2,8 & 0,7 & 11 \\
\hline $\begin{array}{l}\text { R11 - Reputação e/ou visibilidade } \\
\text { perante a sociedade }\end{array}$ & 3,4 & 0,7 & 20 & $-(2)$ & $-(2)$ & \\
\hline $\begin{array}{l}\text { R12 - Aumento da habilidade da } \\
\text { empresa para encontrar e absorver } \\
\text { informações tecnológicas }\end{array}$ & $-(2)$ & - (2) & & 3,3 & 1,0 & 16 \\
\hline $\begin{array}{l}\text { R13 - Obtenção de informações } \\
\text { sobre engenheiros ou cientistas e/ } \\
\text { ou tendências de P\&D nas áreas } \\
\text { científicas }\end{array}$ & $-(2)$ & $-(2)$ & & 3,2 & 0,9 & 16 \\
\hline $\begin{array}{l}\text { R14 - Melhoria de produtos } \\
\text { industriais }\end{array}$ & 3,2 & 1,0 & 16 & 2,7 & 1,0 & 12 \\
\hline $\begin{array}{l}\text { R15 - Contrato de pesquisas que a } \\
\text { empresa não pode realizar }\end{array}$ & $-(2)$ & - (2) & & 3,2 & 0,8 & 15 \\
\hline $\begin{array}{l}\text { R16 - Busca de conselhos de } \\
\text { cunho tecnológico ou consultoria } \\
\text { relacionados à produção }\end{array}$ & - (2) & $-(2)$ & & 2,8 & 1,0 & 16 \\
\hline $\begin{array}{l}\text { R17 - Realização de testes necessários } \\
\text { para produtos e processos da empresa }\end{array}$ & $-(2)$ & - (2) & & 3,0 & 0,8 & 15 \\
\hline $\begin{array}{l}\text { R18 - Melhoria de processos } \\
\text { industriais }\end{array}$ & 3,2 & 1,0 & 17 & 2,7 & 1,0 & 12 \\
\hline $\begin{array}{l}\text { R19 - Equipamentos/instrumentos } \\
\text { de uso compartilhado }\end{array}$ & 2,6 & 0,8 & 18 & 3,1 & 0,7 & 16 \\
\hline $\begin{array}{l}\text { R20 - Recebimento de ajuda no } \\
\text { controle de qualidade }\end{array}$ & $-(2)$ & $-(2)$ & & 2,3 & 0,9 & 14 \\
\hline
\end{tabular}

Fonte: Pesquisa para o projeto Interaçōes de Universidades e Institutos de Pesquisa com Empresas no Rio Grande do Sul. Elaboração dos autores.

(1) Para o cálculo das médias e dos desvios-padrão, foram excluídas as respostas "sem condições de opinar".

(2) Como foram aplicados questionários distintos para grupos de pesquisa e empresas, a comparação entre estas variáveis não foi possível, visto que não eram as mesmas nos dois instrumentos.

(3) Para as razões do tipo R2 e R3, há somente um valor médio para o grupo de respondentes das empresas, pois, para estes, foi questionada apenas a razão relativa aos recursos financeiros, sem dividi-los entre privados e públicos, como foi feito na pergunta destinada aos grupos de pesquisa. 
Importante apontar para o fato de que as ideias para os novos projetos de pesquisa podem ser conceituadas como razóes intelectuais, predominantes nos estudos relativos aos países latino-americanos, conforme indicado por Arza (2010), e Shima e Scatolin (2011), enquanto os recursos financeiros privados classificam-se como razões econômicas, expostas por Arza (2010), D’Este e Perkmann (2011), Porto et al. (2011) e Shima e Scatolin (2011). Os novos produtos e artefatos relacionam-se à ideia de comercialização, que engloba a exploração comercial da tecnologia ou do conhecimento (D'ESTE; PARKMANN, 2011).

Já na concepção das empresas, as principais razões para interagirem com as universidades são a busca por formação de recursos humanos e estudantes, o intercâmbio de conhecimentos ou informaçôes e o incremento na habilidade da empresa de identificar e absorver informaçōes tecnológicas. As motivações menos frequentes foram a melhoria de produtos industriais e a melhoria de processos industriais, além do recebimento de auxílio no controle de qualidade. A menor importância conferida a esses elementos deve estar relacionada ao fato de que a maioria das empresas respondentes pertence ao setor de serviços.

Com esses resultados, destaca-se que as razões que mais motivam as empresas a interagirem com universidades são, predominantemente, do tipo proativas (ARZA, 2010), podendo servir para a geração de atividades inovativas. Tal resultado diverge do que a literatura aponta como sendo mais comumente encontrado em interaçôes U-E em países emergentes, visto que as empresas geralmente buscam resultados que maximizem sua eficiência operacional apenas. Ressalta-se que o intercâmbio de conhecimentos ou informações é a segunda razão mais importante para a interação. Essa constatação deve ser vista como algo interessante, já que, de acordo com a Pesquisa de Inovação Tecnológica (Pintec) (IBGE, 2008), apenas 13,4\% das indústrias brasileiras consideram as universidades fontes de informação importantes para a inovação.

Tanto para os grupos de pesquisa quanto para as empresas, o maior benefício oriundo da interação universidade-empresa, conforme observado na Tabela 2, corresponde aos novos projetos de pesquisa. Esse benefício, classificado como intelectual, já foi constatado como relevante também em estudos realizados em economias desenvolvidas (BONACCORSI; PICCALUGA, 1994) e em desenvolvimento (RAPINI et al., 2009; DUTRÉNIT; ARZA, 2010; FERNANDES et al., 2010). Os demais benefícios para as universidades perpassam a formação de recursos humanos e estudantes e os novos produtos e artefatos, sendo que o segundo benefício também está mencionado em Rapini et al. (2009) para o Brasil, enquanto o terceiro não é citado na literatura como sendo importante para os grupos de pesquisa. 
A melhoria de produtos industriais, as patentes e os softwares foram consideradas vantagens menos importantes, o que deve estar relacionado com a realidade das empresas da amostra: grande parte pequenas e médias e do setor de serviços.

TABELA 2

Grupos de pesquisa e empresas, segundo benefícios da interação universidade-empresa Estado do Rio Grande do Sul - 2013

\begin{tabular}{|c|c|c|c|c|c|c|}
\hline \multirow[b]{2}{*}{ Benefícios da interação } & \multicolumn{3}{|c|}{ Grupos de pesquisa } & \multicolumn{3}{|c|}{ Empresas } \\
\hline & $\begin{array}{l}\text { Média } \\
\text { (1) }\end{array}$ & $\begin{array}{l}\text { Desvio- } \\
\text { padrão } \\
(1)\end{array}$ & $\begin{array}{l}\text { N. de } \\
\text { respon. }\end{array}$ & $\begin{array}{l}\text { Média } \\
\text { (1) }\end{array}$ & $\begin{array}{l}\text { Desvio- } \\
\text { padrão } \\
(1)\end{array}$ & $\begin{array}{l}\text { Média } \\
\text { (1) }\end{array}$ \\
\hline B1 - Novos projetos de pesquisa & 3,6 & 0,6 & 20 & 3,6 & 0,6 & 16 \\
\hline B2 - Novas tecnologias & $-(2)$ & $-(2)$ & & 3,4 & 0,7 & 16 \\
\hline $\begin{array}{l}\text { B3 - Transferência de tecnologia para as } \\
\text { atividades de inovação }\end{array}$ & $-(2)$ & $-(2)$ & & 3,4 & 0,7 & 16 \\
\hline B4 - Formação de RH e estudantes & 3,6 & 0,8 & 20 & $-(2)$ & $-(2)$ & \\
\hline B5 - Novos produtos e artefatos & 3,5 & 0,7 & 19 & 3,0 & 0,9 & 16 \\
\hline B6 - Publicaçōes & 3,4 & 0,7 & 20 & $-(2)$ & $-(2)$ & \\
\hline B7 - Teses e dissertaçōes & 3,4 & 0,6 & 18 & $-(2)$ & $-(2)$ & \\
\hline B8 - Novas descobertas científicas & 3,3 & 0,9 & 20 & 3,5 & 0,6 & 16 \\
\hline B9 - Design & 3,2 & 0,8 & 19 & $-(2)$ & $-(2)$ & \\
\hline B10 - Criação de novas empresas & 3,2 & 0,9 & 19 & $-(2)$ & $-(2)$ & \\
\hline B11 - Educação continuada & 3,2 & 0,9 & 20 & $-(2)$ & $-(2)$ & \\
\hline $\begin{array}{l}\text { B12 - Realização de testes para } \\
\text { produtos e processos da empresa }\end{array}$ & $-(2)$ & $-(2)$ & & 3,2 & 0,8 & 16 \\
\hline B13 - Novos processos industriais & 3,1 & 1,0 & 18 & 2,5 & 1,0 & 12 \\
\hline B14 - Melhoria de processos industriais & 3,1 & 1,0 & 18 & 2,5 & 1,1 & 12 \\
\hline B15 - Software & 3,1 & 1,0 & 20 & $-(2)$ & $-(2)$ & \\
\hline B16 - Patentes & 3,0 & 1,0 & 20 & $-(2)$ & $-(2)$ & \\
\hline $\begin{array}{l}\text { B17 - Aumento das interações com } \\
\text { outras empresas a partir da interação } \\
\text { com a universidade }\end{array}$ & $-(2)$ & $-(2)$ & & 2,8 & 1,0 & 16 \\
\hline $\begin{array}{l}\text { B18 - Uso dos recursos existentes nas } \\
\text { universidades e institutos de pesquisa }\end{array}$ & $-(2)$ & $-(2)$ & & 3,1 & 0,9 & 14 \\
\hline B19 - Melhoria de produtos industriais & 3,0 & 1,1 & 18 & 2,5 & 1,2 & 12 \\
\hline $\begin{array}{l}\text { B20 - Influência sobre a agenda de } \\
\text { P\&D da empresa }\end{array}$ & $-(2)$ & $-(2)$ & & 2,6 & 1,0 & 15 \\
\hline $\begin{array}{l}\text { B21 - Conhecimento tecnológico para } \\
\text { a resolução de problemas de produção }\end{array}$ & $-(2)$ & $-(2)$ & & 2,6 & 1,2 & 15 \\
\hline B22 - Assistência técnica & $-(2)$ & $-(2)$ & & 1,6 & 0,7 & 14 \\
\hline
\end{tabular}

Fonte: Pesquisa para o projeto Interaçōes de Universidades e Institutos de Pesquisa com Empresas no Rio Grande do Sul. Elaboração dos autores.

(1) Para o cálculo das médias e dos desvios-padrão, foram excluídas as respostas "sem condiçôes de opinar".

(2) Como foram aplicados questionários distintos para grupos de pesquisa e empresas, a comparação entre estas variáveis não foi possível, visto que não eram as mesmas nos dois instrumentos. 
Os novos projetos de pesquisa, as novas tecnologias e a transferência delas para as atividades de inovação foram apontados, pelas empresas, como os benefícios mais importantes, constatação que diverge do que é proposto por Dutrénit e Arza (2010) para o contexto latino-americano, visto que os autores alegam que as empresas valorizam mais os benefícios em produção em detrimento daqueles focados em inovação. No entanto, Fernandes et al. (2011) constatam que, no Brasil, a transferência de tecnologia para a inovação já é o terceiro benefício mais importante para as empresas.

Por fim, são apresentados os resultados relativos às dificuldades. Na Tabela 3, observa-se que a burocracia por parte da universidade e as diferenças de prioridades manifestaram-se como as principais dificuldades destacadas por grupos de pesquisa e por empresas. Essas questōes são abordadas, principalmente, por Segatto (1996), Shima e Scatolin (2011) e Freitas, Marques e Silva (2013) como uma característica brasileira presente na interação U-E. Contudo, ressalta-se que se a burocracia for analisada individualmente, considerando o fato de a universidade ser pública ou privada, verifica-se que há diferenças entre as médias. Enquanto para as universidades públicas a burocracia tem uma média de 3,7, para as privadas essa média é de apenas 3,0. Entende-se, assim, que os mecanismos adotados pelas universidades públicas para regular as interações parecem ser mais complexos.

O desconhecimento, por parte da empresa, de seus objetivos para a pesquisa, dificuldade também exposta pelos grupos, não é apresentada na teoria, pois essa variável foi incluída no instrumento de pesquisa com base nas inferências feitas pelos líderes dos grupos de pesquisa na fase de validação de conteúdo do questionário. Esse resultado suscitou uma nova variável que ainda não era discutida e apontada como uma dificuldade, sendo, então, importante investigá-la em estudos futuros.

A divergência quanto ao prazo da pesquisa foi uma barreira que, levantada pelas empresas, encontra respaldo nas proposiçōes feitas por Segatto (1996). Por fim, a perda de liberdade no processo de investigação também apresentou uma média relativamente baixa no constructo dificuldades, conclusão que corrobora com Mowery e Sampat (2005), que afirmam que as universidades deixaram de ser "torres de marfim", voltadas apenas para a obtenção do conhecimento, para se tornarem atores estratégicos no processo de busca pela inovação.

Para resumir os principais resultados obtidos na pesquisa, é apresentado o Quadro 2, o qual destaca as principais razões, benefícios e dificuldades da interação U-E - definidos como aqueles que apresentaram as três maiores médias nas Tabelas 1,2 e $3-$, para os dois conjuntos de respondentes. 
TABELA 3

Grupos de pesquisa e empresas, segundo dificuldades da interação universidade-empresa Estado do Rio Grande do Sul - 2013

\begin{tabular}{|c|c|c|c|c|c|c|}
\hline \multirow[b]{2}{*}{ Dificuldades da interaçáo } & \multicolumn{3}{|c|}{ Grupos de pesquisa } & \multicolumn{3}{|c|}{ Empresas } \\
\hline & $\begin{array}{l}\text { Média } \\
(1)\end{array}$ & $\begin{array}{l}\text { Desvio- } \\
\text { padrão } \\
(1)\end{array}$ & $\begin{array}{l}\text { N. de } \\
\text { respon. }\end{array}$ & $\begin{array}{l}\text { Média } \\
(1)\end{array}$ & $\begin{array}{l}\text { Desvio- } \\
\text { padrão } \\
\text { (1) }\end{array}$ & $\begin{array}{l}\text { N. de } \\
\text { respon. }\end{array}$ \\
\hline $\begin{array}{l}\text { D1 - Burocracia por parte da } \\
\text { universidade }\end{array}$ & 3,3 & 0,9 & 19 & 3,9 & 0,4 & 15 \\
\hline D2 - Diferença de prioridades & 3,2 & 1,0 & 18 & 3,9 & 0,4 & 14 \\
\hline $\begin{array}{l}\text { D3 - Desconhecimento, por parte } \\
\text { da empresa, de seus objetivos para a } \\
\text { pesquisa }\end{array}$ & 3,2 & 0,7 & 19 & $-(2)$ & $-(2)$ & \\
\hline $\begin{array}{l}\text { D4 - Falta de conhecimento nas } \\
\text { empresas das atividades realizadas nas } \\
\text { universidades }\end{array}$ & 3,1 & 1,0 & 19 & $-(2)$ & - (2) & \\
\hline $\begin{array}{l}\text { D5 - Falta de conhecimento nas } \\
\text { empresas sobre como ocorre o processo } \\
\text { de interação }\end{array}$ & 3,1 & 0,7 & 19 & $-(2)$ & $-(2)$ & \\
\hline $\begin{array}{l}\text { D6 - Falta de conhecimento das } \\
\text { necessidades das empresas por parte das } \\
\text { universidades }\end{array}$ & 3,1 & 0,9 & 19 & 3,3 & 0,6 & 16 \\
\hline D7 - Custeio da pesquisa & 3,1 & 0,8 & 18 & 3,0 & 0,9 & 15 \\
\hline D8 - Divergência de objetivos & 3,0 & 1,0 & 19 & 3,5 & 0,8 & 16 \\
\hline $\begin{array}{l}\text { D9 - Falta de pessoal qualificado para } \\
\text { estabelecer um diálogo nas empresas }\end{array}$ & 2,9 & 0,8 & 19 & 2,0 & 0,8 & 14 \\
\hline D10 - Burocracia por parte da empresa & 2,9 & 1,0 & 19 & 1,9 & 1,0 & 15 \\
\hline D11 - Direitos de propriedade & 2,9 & 1,1 & 18 & 3,1 & 0,9 & 15 \\
\hline $\begin{array}{l}\text { D12 - Os pesquisadores da univer- } \\
\text { sidade são muito orientados cientifi- } \\
\text { camente }\end{array}$ & $-(2)$ & $-(2)$ & & 3,3 & 1,1 & 13 \\
\hline $\begin{array}{l}\text { D13 - Divergência quanto ao prazo } \\
\text { da pesquisa }\end{array}$ & 2,7 & 0,9 & 19 & 3,6 & 0,6 & 14 \\
\hline $\begin{array}{l}\text { D14 - Divergência entre o conheci- } \\
\text { mento disponibilizado pela universi- } \\
\text { dade e o conhecimento necessário à } \\
\text { empresa }\end{array}$ & - (2) & $-(2)$ & & 2,8 & 0,9 & 15 \\
\hline $\begin{array}{l}\text { D15 - Falta de pessoal qualificado } \\
\text { para estabelecer um diálogo nas } \\
\text { universidades }\end{array}$ & 2,7 & 0,9 & 19 & 2,8 & 1,0 & 14 \\
\hline $\begin{array}{l}\text { D16 - Perda de liberdade no processo } \\
\text { de investigaçáo }\end{array}$ & 2,6 & 1,0 & 19 & $-(2)$ & $-(2)$ & \\
\hline D17 - Problemas de confiança & 2,6 & 1,1 & 19 & 3,0 & 0,8 & 15 \\
\hline $\begin{array}{l}\text { D18 - Falhas na comunicação devido } \\
\text { ao excesso de interlocutores }\end{array}$ & 2,4 & 0,8 & 19 & $-(2)$ & $-(2)$ & \\
\hline D19 - Distância geográfica & 2,1 & 0,9 & 19 & 1,9 & 1,0 & 14 \\
\hline $\begin{array}{l}\mathrm{D} 20 \text { - Os pesquisadores da } \\
\text { universidade não são suficientemente } \\
\text { orientados cientificamente }\end{array}$ & $-(2)$ & - (2) & & 2,1 & 0,9 & 12 \\
\hline
\end{tabular}

Fonte: Pesquisa para o projeto Interaçôes de Universidades e Institutos de Pesquisa com Empresas no Rio Grande do Sul. Elaboração dos autores.

(1) Para o cálculo das médias e dos desvios-padrão, foram excluídas as respostas "sem condiçôes de opinar".

(2) Como foram aplicados questionários distintos para grupos de pesquisa e empresas, a comparação entre estas variáveis não foi possível, visto que năo eram as mesmas nos dois instrumentos. 
QUADRO 2

Principais razóes, benefícios e dificuldades da interação universidade-empresa apontados pelos grupos de pesquisa e empresas

Estado do Rio Grande do Sul - 2013

\begin{tabular}{|c|c|c|c|}
\hline & $\begin{array}{l}\text { Categorias de } \\
\text { variáveis }\end{array}$ & Grupos de Pesquisa & Empresas \\
\hline \multirow[t]{4}{*}{ Razóes } & $\begin{array}{l}\text { Conhecimento e } \\
\text { tecnologia }\end{array}$ & $\begin{array}{l}\text { R1 - Ideias para novos } \\
\text { projetos de cooperação }\end{array}$ & $\begin{array}{l}\text { R6 - Formação de RH e } \\
\text { estudantes } \\
\text { R5 - Intercâmbio de } \\
\text { conhecimento ou informações } \\
\text { R12 - Aumento da habilidade } \\
\text { da empresa de encontrar } \\
\text { e absorver informações } \\
\text { tecnológicas }\end{array}$ \\
\hline & Acesso a recursos & $\begin{array}{l}\text { R2 - Recursos } \\
\text { financeiros privados }\end{array}$ & (2) \\
\hline & Industrial & $\begin{array}{l}\mathrm{R} 4-\text { Novos produtos e } \\
\text { artefatos }\end{array}$ & - \\
\hline & Institucional & - & - \\
\hline \multirow{4}{*}{ Benefícios } & Institucional & $\begin{array}{l}\text { B4 - Formação de RH e } \\
\text { estudantes }\end{array}$ & - \\
\hline & Produtos/processos & $\begin{array}{l}\text { B5 - Novos produtos e } \\
\text { artefatos }\end{array}$ & ( \\
\hline & Projetos & $\begin{array}{l}\text { B1 - Novos projetos de } \\
\text { pesquisa }\end{array}$ & $\begin{array}{l}\text { B1 - Novos projetos de } \\
\text { pesquisa } \\
\text { B2 - Novas tecnologias } \\
\text { B3 - Transferência de } \\
\text { tecnologia para as atividades de } \\
\text { inovação } \\
\text { B8 - Novas descobertas } \\
\text { científicas }\end{array}$ \\
\hline & Rec. financeiros & - & - \\
\hline \multirow{5}{*}{ Dificuldades } & Institucional & $\begin{array}{l}\text { D1 - Burocracia por } \\
\text { parte da universidade } \\
\text { D3 - Desconhecimento } \\
\text { por parte da empresa } \\
\text { de seus objetivos de } \\
\text { pesquisa }\end{array}$ & $\begin{array}{l}\text { D1 - Burocracia por parte da } \\
\text { universidade }\end{array}$ \\
\hline & $\begin{array}{l}\text { Independência } \\
\text { científica }\end{array}$ & 然 & - \\
\hline & Interesses & $\begin{array}{l}\text { D2 - Diferenças de } \\
\text { prioridades }\end{array}$ & $\begin{array}{l}\text { D2 - Diferenças de prioridades } \\
\text { D13 - Divergência quanto ao } \\
\text { prazo da pesquisa }\end{array}$ \\
\hline & Rec. humanos & - & - \\
\hline & Geografia & - & - \\
\hline
\end{tabular}

Fonte: Pesquisa para o projeto Interaçōes de Universidades e Institutos de Pesquisa com Empresas no Rio Grande do Sul. Elaboração dos autores. 
As principais razões destacadas na pesquisa estão distribuídas nas categorias de conhecimento e tecnologia, acesso a recursos financeiros e industriais. Não foram observados motivos na categoria institucional. As razões destacadas no Quadro 2 também podem ser definidas como intelectuais (R1) e econômicas (R2 e R4). Em relação à visão das empresas, as motivações mais importantes estão na categoria de conhecimento e tecnologia e, assim, convergentes com aquelas observadas no caso dos grupos. Não se destacou, por exemplo, a razão relativa a recursos financeiros: as empresas poderiam estabelecer interações para obterem recursos financeiros, por exemplo, via editais de subvenção econômica que estimulam a interação, mas isso não se caracteriza como razão principal. Essa resposta pode ser facilmente compreendida quando se consideram os resultados da Pintec (IBGE, 2010), que revelam que as empresas pouco conhecem sobre esse tipo de fonte de fomento e também que pouco utilizam-no.

No que diz respeito aos benefícios, foi percebido pelos grupos de pesquisa que os mais importantes são de ordem institucional e desenvolvimento de produtos, processos e projetos. Na visão das empresas, os benefícios considerados mais relevantes concentram-se na categoria de desenvolvimento de novos projetos. Desperta interesse compreender o motivo pela qual os benefícios relativos a "recursos financeiros" não receberem destaque. No caso das empresas, entende-se que essa constatação, a qual, de certa forma, também corrobora os achados da Pintec (IBGE, 2010), baseia-se no fato de que ainda relativamente poucas são as empresas brasileiras que afirmam utilizar recursos financeiros de terceiros (seja na forma de subvenção, seja na forma de crédito, por exemplo), para realizarem suas atividades de inovação; e isso parece não ser diferente quando utilizam o mecanismo da interação U-E.

Por fim, as principais dificuldades apontadas foram classificadas como institucionais, destacando-se a burocracia, e de interesse, em que emergem as diferenças relativas a prioridades e prazos. Não foram destacadas, como as mais relevantes, as dificuldades referentes a independência científica, recursos humanos e geografia.

Para finalizar, de acordo com a maioria das empresas pesquisadas $(62,5 \%)$, as interaçōes têm sido um sucesso para atingir os objetivos da empresa. Já $25 \%$ das empresas pesquisadas acreditam que os objetivos ainda serão atingidos em tempo hábil. Somente $12,5 \%$ afirmam que a interação não tem tido sucesso na obtenção dos objetivos. 


\section{Discussão}

Com o objetivo de avançar nas análises, dois esforços foram feitos. O primeiro referiu-se à aplicação do Teste-T para verificar a existência de diferenças estatisticamente significativas nas características da interação universidade-empresa entre os grupos de pesquisa e as empresas. Os resultados apontaram que somente algumas médias possuíam diferenças, ${ }^{5}$ indicando pouca relevância em avançar na discussão desses resultados.

O segundo esforço foi o de trabalhar com a proposição de hipóteses plausíveis. A ideia de utilizar esse mecanismo surgiu do fato de que não foram encontrados na literatura estudos que relacionassem os elementos identificados como razões, benefícios e dificuldades. Ou seja, não foram identificadas hipóteses que relacionassem entre si razões, benefícios e dificuldades da interação universidade-empresa que tenham sido construídas com base em evidências empíricas e pudessem, assim, ser testadas nesta pesquisa.

Por conta disso, não foi possível utilizar o que é denominado de hipótese empírica. Optou-se, portanto, por analisar o que é conceituado de hipótese plausível, que pode ser compreendida por não ter, a priori, uma explicação baseada em um conhecimento científico comprovado, sendo oriunda de deduçóes lógicas do conhecimento aceito.

Ao todo foram elaboradas seis hipóteses, três referentes aos grupos de pesquisa e três relativas às empresas, as quais são apresentadas e justificadas a seguir. Para analisá-las, utilizou-se o cálculo da Correlação de Spearman com nível de significância de $95 \%$ e de $99 \%$, tendo sido definidas forças de associação moderada ( $\rho=$ $0,41 \geq 0,70)$ e forte $(\rho=0,71 \geq 0,90)$ (HAIR et al., 2005).

Os resultados das correlações propostas encontram-se na Tabela 4.

5 Considerando-se duas amostras independentes com um nível de significância de 95\%, constatou-se que apenas quatro razōes e cinco dificuldades apresentaram diferenças significativas. 
TABELA 4

Correlação de Spearman correspondente às hipóteses plausíveis

\begin{tabular}{|c|c|c|c|c|c|}
\hline & & \multicolumn{2}{|c|}{ Grupos de pesquisa } & \multicolumn{2}{|c|}{ Empresa } \\
\hline & & $\begin{array}{l}\text { Novos } \\
\text { projetos de } \\
\text { pesquisa }\end{array}$ & $\begin{array}{c}\text { Novos } \\
\text { produtos } \\
\text { e artefatos }\end{array}$ & $\begin{array}{l}\text { Novas } \\
\text { tecnolo- } \\
\text { gias }\end{array}$ & $\begin{array}{c}\text { Transferência de } \\
\text { tecnologia para } \\
\text { as atividades de } \\
\text { inovação }\end{array}$ \\
\hline \multirow{3}{*}{$\begin{array}{l}\text { Grupos } \\
\text { de } \\
\text { pesquisa }\end{array}$} & $\begin{array}{l}\text { Ideias para novos } \\
\text { projetos de } \\
\text { cooperação }\end{array}$ & 0,277 & - & - & - \\
\hline & $\begin{array}{l}\text { Novos produtos } \\
\text { e artefatos }\end{array}$ & - & $0,684^{* *}$ & - & - \\
\hline & $\begin{array}{l}\text { Diferença de } \\
\text { prioridades }\end{array}$ & 0,301 & - & - & - \\
\hline \multirow{3}{*}{ Empresas } & $\begin{array}{l}\text { Aumentar a } \\
\text { habilidade da } \\
\text { empresa para } \\
\text { encontrar e absorver } \\
\text { informaçóes } \\
\text { tecnológicas }\end{array}$ & - & - & 0,326 & $0,831^{* *}$ \\
\hline & $\begin{array}{l}\text { Intercâmbio de } \\
\text { conhecimentos } \\
\text { ou informações }\end{array}$ & - & - & 0,379 & $0,603^{*}$ \\
\hline & $\begin{array}{l}\text { Divergência quanto } \\
\text { ao prazo da pesquisa }\end{array}$ & - & - & - & $-0,793^{* *}$ \\
\hline
\end{tabular}

Fonte: Elaborada pelos autores.

* correlação com nível de significância de $95 \%$; ** correlação com nível de significância de $99 \%$.

Nota: Os resultados das correlaçōes que estão com um traço (-) não são apresentados pois não foram analisados nas hipóteses plausíveis propostas.

\section{Hipóteses para os grupos de pesquisa}

- Interagir para ter "ideias de novos projetos de cooperação" (R1) possui relação direta com o beneficio referente aos "novos projetos de pesquisa" (B1). Essa hipótese foi estruturada por acreditar-se que grupos de pesquisa que interagem com o intuito de ter ideias para novos projetos de cooperação obtêm como benefício da interação novos projetos de pesquisa, propondo-se uma leitura do benefício como uma consequência direta da razão que motivou a interação.

A hipótese não se confirmou, indicando que a relação entre razão e benefício deve ser compreendida de forma mais complexa, pelo menos no caso em que a razão verificada possua significado amplo, como ocorre em "ideias para novos projetos de cooperação". 
- Interagir para desenvolver "novos produtos e artefatos" (R4) é uma razão que possui relação direta com "novos produtos e artefatos" como benefício (B5). De forma similar à hipótese anterior, a justificativa de propor tal relação encontra-se no entendimento de que interaçóes estabelecidas para desenvolver novos produtos devem gerar como benefício os próprios novos produtos planejados.

Essa hipótese foi comprovada com a constatação de uma correlação direta moderada entre R4 e B5, podendo-se inferir que grupos de pesquisa que interagem motivados a desenvolver "novos produtos e artefatos" atingem esses objetivos específicos, tendo como um dos principais benefícios a própria geração dos produtos. Assim, parece que, ao se estabelecerem interaçōes com razões pontuais, como a R4, os resultados gerados dizem respeito ao objetivo específico determinado na interação.

- A dificuldade relativa à diferença de prioridades (D2) possui relação inversa com os beneficios referentes aos novos projetos de pesquisa (B1). Nesse sentido, entende-se que a diferença de prioridades limitaria a concretização de novos projetos entre grupos de pesquisa e empresas, sendo que a importância dada a essa dificuldade coloca-se como obstáculo no que compete aos benefícios referentes ao estabelecimento de novos projetos conjuntos. A hipótese não se confirmou, revelando que as diferenças de prioridades elemento tradicionalmente relatado como caraterístico nos estudos sobre as interaçôes U-E - foi uma dificuldade apontada como relevante, mas não se caracteriza como um fator condicionante para a não obtenção do benefício relativo a "novos projetos de pesquisa".

\section{Hipóteses para as empresas}

- Aumentar a habilidade da empresa para encontrar e absorver informações tecnológicas (R12) possui relação direta com os beneficios referentes às novas tecnologias (B2) e à transferência de tecnologia para as atividades de inovação (B3). As empresas que interagem motivadas a aumentar sua habilidade para encontrar e absorver informaçōes tecnológicas têm como benefícios o acesso a novas tecnologias e a transferência de tecnologia para as atividades de inovação, visto que tanto a razão quanto os benefícios expostos evidenciam a busca pelo aumento da capacidade da empresa de inovar. Essa hipótese confirmou-se em parte. Foi identificada uma forte correlação direta entre o "aumento na habilidade da empresa para encontrar e absorver 
informaçôes tecnológicas" com os benefícios relacionados à "transferência de tecnologia para as atividades de inovação". Isso faz sentido também quando se relaciona com a ideia de que quanto maior é a capacidade de absorção (de conhecimentos e tecnologias) das firmas, maior pode ser o benefício que esta tem com a transferência de tecnologia para realizar suas atividades de inovação. Destaca-se que a R12 é uma razão do tipo proativa e o $\mathrm{B} 3$ constitui um benefício voltado à inovação.

Já a relação proposta entre R12 e as "novas tecnologias" não se confirmou.

- Intercâmbio de conhecimentos ou informaçōes é uma razão (R5) que possui relaçāo direta com os beneficios referentes às novas tecnologias (B2) e à transferência de tecnologia para as atividades de inovação (B3). Como exposto na hipótese anterior, o intercâmbio de conhecimentos ou informações pode ser interpretado como um motivo que leva a empresa a obter como benefício da interação o acesso às novas tecnologias e a transferência delas para as atividades de inovação; sendo assim, entende-se que conhecimentos e informações auxiliam as empresas na aquisição e utilização de novas tecnologias.

Para essa hipótese, pode-se observar o mesmo resultado encontrado na anterior, ou seja, há uma correlação direta moderada entre o "intercâmbio de conhecimentos ou informaçôes" com o benefício relativo à "transferência de tecnologia para as atividades de inovação". Porém, não se confirma a hipótese quando "novas tecnologias" são consideradas benefício, como ocorreu na hipótese anterior. Assim, apesar de o benefício "novas tecnologias" ser entendido como um dos mais importantes pelas empresas, esse não apresentou relação direta com as razões (R5 e R12) relacionadas à atividade de inovação da firma.

- A divergência quanto ao prazo da pesquisa (D13) possui relação inversa como beneficio referente à transferência de tecnologia para as atividades de inovação (B3). De acordo com a literatura referente às empresas localizadas em países emergentes, os principais benefícios identificados para as empresas são os de curto prazo, em detrimento daqueles focados em inovação, concentrados no longo prazo. Logo, a dificuldade "divergência quanto ao prazo" é proposta aqui como um elemento limitante na obtenção de benefícios relativos à atividade de inovação da firma, ou seja, ao benefício B3.

Essa hipótese foi confirmada, reforçando a ideia da existência de um distanciamento cultural entre universidades e empresas, já que as firmas 
precisam responder à dinâmica de mercado e, para isso, buscam resultados de curto prazo para usufruir dos benefícios da inovação, enquanto as universidades movimentam-se em um ritmo usualmente mais lento, ditado pelo desenvolvimento do conhecimento científico e tecnológico, além da questão da burocracia já destacada anteriormente, que também dificulta e retarda a realização e a conclusão das atividades da interação U-E.

O exercício de proposição e análise das hipóteses plausíveis proporcionou a verificação de que as relações existentes entre razões, benefícios e dificuldades da interação U-E apresenta-se complexa para o conjunto de respondentes envolvidos com a área de conhecimento de ciências da computação do Rio Grande do Sul. Isso porque não necessariamente as razões e dificuldades apontadas como relevantes apresentam relação com os benefícios e dificuldades também considerados importantes. Entende-se que isso reflete os diversos elementos que influenciam as interaçôes e tal complexidade precisa ser levada em conta para analisar as interaçôes.

\section{Considerações finais}

O objetivo central do estudo foi analisar as principais características das razóes, benefícios e dificuldades da interação U-E. Na tentativa de verificar se é possível "ir além de pontos de interação" ou "manchas de interação", conforme mencionado pela literatura nacional como uma característica da interação U-E no Brasil, apresentou-se uma pesquisa survey realizada com grupos de pesquisa e empresas vinculadas à área de conhecimento das ciências da computação no Rio Grande do Sul, em 2013.

É importante mencionar que, em relação às limitações da pesquisa, o estudo foi realizado com grupos de pesquisa de uma área específica do conhecimento, localizados no Rio Grande do Sul, que indicaram as empresas com as quais consideravam ter relacionamentos de destaque para compor o conjunto de firmas investigadas. Além disso, grande parte da amostra era formada por pequenas e médias empresas. Portanto, os resultados precisam ser contextualizados e, ainda que os vieses presentes na investigação reduzam a capacidade do estudo em direção a generalizações dos resultados, esses não perdem importância e merecem ser aqui destacados.

As razões e benefícios apontados pelos respondentes centram-se em elementos relacionados à geração de conhecimento e tecnologia e à atividade de inovação do grupo e da firma. As dificuldades apontam, centralmente, para questôes institucionais e de interesse. 
No que diz respeito às relações propostas entre os três constructos pesquisados, destaca-se a verificação de apenas uma no caso dos grupos de pesquisa: a relação entre a razão e o benefício de desenvolver "novos produtos e artefatos". Emerge da pesquisa, portanto, a relação entre uma razão do tipo industrial com um benefício relacionado à geração de inovações de produto. Ambos fatores foram destacados como de elevada importância pelos grupos de pesquisa e representam, portanto, a percepção destes de que o papel desempenhado por eles nas interações vai além do que tradicionalmente poderia ser esperado - como, por exemplo, qualificar recursos humanos e focar na geração de conhecimento científico para a universidade -, ao destacarem a aplicabilidade do conhecimento quando definem como razões e benefícios relevantes aqueles que traduzem a aplicação do conhecimento. Vale observar que o fato de a pesquisa ter sido feita em uma área - ciências da computação - que tem um viés de aplicação do conhecimento deve ter influenciado as respostas.

Já para as empresas, foram identificadas três relaçôes. Todas elas dizem respeito à atividade de inovação da firma. As duas primeiras relacionam razões da categoria "conhecimento e tecnologia" com benefícios classificados como de "projetos". A última relaciona uma dificuldade institucional - divergência quanto a prazos - com um benefício referente à transferência de tecnologia para as atividades de inovação, indicando uma relação inversa, ou seja, a dificuldade institucional influencia negativamente a obtenção de um benefício para a atividade de inovação da firma.

As descobertas da investigação aqui apresentada sugerem três reflexões. A primeira refere-se à constatação da inexistência de correlação em algumas das hipóteses plausíveis propostas, sugerindo que as relações entre razões, benefícios e dificuldades são dotadas de uma complexidade não capturada na pesquisa. A segunda reflexão remete ao fato de o foco das respostas a respeito das razões e benefícios para os grupos de pesquisa e empresas estar na geração de conhecimento e tecnologia, no desenvolvimento de produtos, processos e projetos, indicando que as interações estabelecidas vão além do tradicional papel atribuído às universidades - o qual compreende a oferta de ensino superior e a produção de conhecimento científico -, e que as empresas percebem os grupos de pesquisa como atuantes na realização das suas atividades de inovação, visto que valorizam as razōes classificadas como proativas e os benefícios para a inovação na relação com as universidades.

A terceira reflexão diz respeito à questão institucional, a qual não se destaca enquanto razão para o estabelecimento das interaçôes, mas é considerada um importante benefício pelos grupos de pesquisa - refletindo a função tradicional das universidades de formação de recursos humanos e estudantes - e uma relevante 
dificuldade por ambos respondentes, devido principalmente à questão da burocracia. Esse último fator reflete as diferenças culturais entre os atores envolvidos, bem como o desconhecimento destes das necessidades de cada um. Com vistas a estimular o estabelecimento e sucesso das interações U-E, sugere-se que tal elemento seja alvo de melhorias, tanto nas universidades públicas quanto nas privadas.

O conjunto de resultados apresentados permite concluir que as interações U-E dos grupos de pesquisa da área de conhecimento de ciências da computação do Rio Grande do Sul com empresas desempenham importante papel na geração de conhecimento e inovaçōes para ambos atores. As atividades tradicionais das universidades são apontadas como relevantes e também entendidas como benefício por parte das empresas, mas outras também se destacam, conferindo um papel importante para os grupos de pesquisa nas atividades de inovação das firmas. As empresas também surpreenderam ao entenderem que a contribuição da universidade pode e deve ir além da sua função de instituição de ensino e pesquisa acadêmica.

Assim, a ideia de ir além de "pontos de interação" entre U-E remete não apenas à expansão quantitativa do número de grupos de pesquisa e empresas que estabelecem interações U-E, mas também à qualidade das interaçôes realizadas, levando ao entendimento de que essas podem, de fato, contribuir diretamente para a atividade de geração e difusão de conhecimentos e inovaçôes. Os resultados apontam para tal cenário, bem como desmistificam a ideia das universidades como "torres de marfim" e das empresas como atores passivos e focados somente em benefícios para a produção.

Para estudos futuros, sugere-se ampliar as áreas de conhecimento, as regióes, os setores produtivos investigados e o porte das empresas, no sentido de possibilitar um olhar para as especificidades de cada um destes fatores.

\section{Referências bibliográficas}

ALBUQUERQUE, E. M. Immature systems of innovation: introductory notes about a comparison between South Africa, India, Mexico and Brazil based on science and technology statistics. Belo Horizonte: UFMG/Cedeplar, 2003 (Texto para discussão, 221).

ARVANITIS, S.; KUBLI, U.; WOERTER, M. University-industry knowledge and technology transfer in Switzerland: What university scientists think about co-operation with private enterprises. Research Policy, v. 37, n. 10, p. 1865-1883, 2008.

University-industry knowledge and technology transfer in Switzerland: the university view. Zurich: KOF Swiss Economic Institute, 2005 (KOF working paper, n. 119). 
ARZA, V. Channels, benefits and risks of public-private interactions for knowledge transfer: a conceptual framework inspired by Latin America. Science and Public Policy, v. 37, n. 7, p. $473-484,2010$.

BONACCORSI, A.; PICCALUGA, A. A theoretical framework for the evaluation of university-industry relationships. $R \& D$ Management, v. 24, n. 3, p. 229-247, 1994.

COHEN, W. M.; NELSON, R. R.; WALSH, J. P. Links and Impacts: the influence of public research on industrial R\&D. Management Science, v. 48, n. 1, p. 1-23, 2002.

COSTA, A. B.; RUFFONI, J.; PUFFAL, D. Proximidade geográfica e interação universidade-empresa no Rio Grande do Sul. Revista de Economia, v. 37, n. especial, p. 213-238, 2011.

D'ESTE, P.; PERKMANN, M. Why do academics engage with industry? The entrepreneurial university and individual motivations. Journal of Technology Tranfer, v. 36, n. 3, p. 316-339, 2011.

DUTRÉNIT, G.; ARZA, V. Channels and benefits of interactions between public research organizations and industry: comparing four Latin American countries. Science and Public Policy, v. 37, n. 7, p. 541-553, 2010.

EDQUIST, C. Systems of innovation: technologies, institutions and organizations. London: Pinter, 1997.

FELLER, I.; AILES, C. P.; ROESSNER, J. D. Impacts of research universities on technological innovation in industry: evidence from engineering research centers. Research Policy, v. 31, p. 457-474, 2002.

FERNANDES, A. C.; SOUZA, B. C.; SILVA, A. S.; SUZIGAN, W.; CHAVES, C. V.; ALBUQUERQUE, E. Academy-industry links in Brazil: evidence about channels and benefits for firms and researchers. Science and Public Policy, v. 37, n. 7, p. 485-498, 2010.

FREEMAN, C. Technology policy and economic performance: lesson from Japan. London/ New York: Pinter Publishers, 1987.

. "The National System of Innovation" in historical perspective. Cambridge Journal of Economics, v. 19, n. 1, 1995.

FREITAS, I. M. B.; MARQUES, R. A.; SILVA, E. M. P. University-industry collaboration and innovation in emergent and mature industries in new industrialized countries. Research Policy, v. 42, n. 2, p. 443-453, 2013.

HAIR, J. F.; BABIN, B.; MONEY, A. H.; SOMOUEL, P. Fundamentos de métodos de pesquisa em administração. Porto Alegre: Bookman, 2005. 
IBGE - Instituto Brasileiro de Geografia e Estatística. Pesquisa de Inovação Tecnológica 2008. Rio de Janeiro: Ministério do Planejamento, Orçamento e Gestão, 2010.

KLEVORICK, A.; LEVIN, R.; NELSON, R.; WINTER, S. On the sources and significance of interindustry differences in technological opportunities. Research Policy, v. 24, n. 2, p. 185-205, 1995.

MAZZOLENI, R.; NELSON, R. The roles of research at universities and public labs in economic catch-up. Research Policy, v. 36, n. 10, p. 1512-1528, 2007.

MEYER-KRAHMER, F.; SCHMOCH, U. Science-based technologies: industry-university interactions in four fields. Research Policy, v. 27, n. 8, p. 835-851, 1998.

MOWERY, D.; SAMPAT, B. Universities in national systems. In: FAGERBERG, J.; MOWERY, D.; NELSON, R. The Oxford handbook of innovation. Oxford: Oxford University Press, 2005, p. 209-239.

NELSON, R. R.; ROSENBERG, N. Technical innovation and national systems. In: NELSON, R. R. National Innovation Systems: a comparative analysis. Oxford: Oxford University Press, 1993.

PORTO, G. S.; KANNEBLEY JÚNIOR, S.; SELAN, B.; BARONI, J. P. M. T. Redes de interação universidade-empresa no Brasil: uma análise de redes sociais. Revista de Economia, v. 37, n. especial, p. 9-24, 2011.

PÓVOA, L. M. C. A crescente importância das universidades e institutos públicos de pesquisa no processo de catching-up tecnológico. In: Seminário sobre a Economia Mineira Cedepelar, 12, 2008, Belo Horizonte. Anais... Belo Horizonte: Universidade Federal de Minas Gerais, 2008.

PRAGER, O. J.; OMENN, G. S. Research, innovation and university-industry linkages. Science, v. 207, n. 25, p. 379-384, 1980.

RAPINI, M. S. Interação universidade-empresa no Brasil: evidências do Diretório dos Grupos de Pesquisa no Brasil. Estudos Econômicos, v. 37, n. 2, p. 212-233, 2007.

RAPINI, M. S.; SUZIGAN, W.; FERNANDES, A. C.; DOMINGUES, E.; CARVALHO, S. S. M.; CHAVES, C. V. A contribuição das universidades e institutos de pesquisa para o Sistema de Inovação Brasileiro. In: Encontro Nacional de Economia, 37, 2009, Foz do Iguaçu. Anais... Foz do Iguaçu: Anpec, 2009.

REIS, D. R. The professor as innovation agent in the interaction process with company. In: International Conferences on Technology Policy and Innovation, 2, 1998, Lisboa. Anais... Lisboa: IST, 1998. 
ROSENBERG, N. Schumpeter and the endogeneity of technology: some American perspectives. London: Routledge, 2000.

ROSENBERG, N.; NELSON, R. R. American universities and technical advance in industry. Research Policy, v. 23, n. 3, p. 323-348, 1994.

SEGATTO, A. P. Análise do processo de cooperação tecnológica universidade-empresa: um estudo exploratório. 1996. Dissertação (Mestrado em Administração) - Departamento de Administração da Faculdade de Economia, Administração e Contabilidade da Universidade de São Paulo, São Paulo, 1996.

SEGATTO-MENDES, A. P.; SBRAGIA, R. O processo de cooperação universidade-empresa em universidades brasileiras. Revista de Administração, v. 37, n. 4, p. 58-71, 2002.

SHIMA, W. T.; SCATOLIN, F. D. Uma comparação das universidades/institutos de pesquisa e das empresas sobre o processo de interação. Revista de Economia, v. 37, n. especial, p. 213-238, 2011.

SUZIGAN, W.; ALBUQUERQUE, E. M. A interação entre universidades e empresas em perspectiva histórica no Brasil. In: SUZIGAN, W.; ALBUQUERQUE, E. M.; CARIO, S. A. F. Em busca da inovação: interação universidade-empresa no Brasil. São Paulo: Autêntica, 2011.

TARTARI, V.; BRESCHI, S. Set them free: scientists' evaluations of the benefits and costs of university-industry research collaboration. Industrial and Corporate Change, v. 21, n. 5, p. 1117-1147, 2012. 